\title{
Elafin is a biomarker of graft versus host disease of the skin
}

\author{
Sophie Paczesny ${ }^{1}$, Thomas M Braun ${ }^{2}$, John E Levine ${ }^{1,3}$, Jason Hogan ${ }^{4}$, Jeffrey Crawford ${ }^{1}$, \\ Bryan Coffing ${ }^{5}$, Stephen Olsen ${ }^{5}$, Sung W Choi $^{1}$, Hong Wang ${ }^{4}$, Vitor Faca ${ }^{4}$, Sharon Pitteri ${ }^{4}$, \\ Qing Zhang ${ }^{4}$, Alice Chin ${ }^{4}$, Carrie Kitko ${ }^{1}$, Shin Mineishi ${ }^{3}$, Gregory Yanik ${ }^{1}, 3$, Edward \\ Peres $^{1,3}$, David Hanauer ${ }^{1}$, Ying Wang ${ }^{1}$, Pavan Reddy ${ }^{3}$, Samir Hanash ${ }^{4}$, and James LM \\ Ferrara $1,3,{ }^{*}$ \\ ${ }^{1}$ Department of Pediatrics, University of Michigan, Ann Arbor, MI 48109, USA \\ 2 Department of Biostatistics, University of Michigan, Ann Arbor, MI 48109, USA \\ ${ }^{3}$ Department of Internal Medicine, University of Michigan, Ann Arbor, MI 48109, USA \\ ${ }^{4}$ Molecular Diagnostics Program, Fred Hutchinson Cancer Research Center, Seattle, WA 98109, \\ USA \\ ${ }^{5}$ Department of Pathology, University of Michigan, Ann Arbor, MI 48109, USA
}

\begin{abstract}
Graft-versus-host-disease (GVHD), the major complication of allogeneic bone marrow transplantation (BMT), affects the skin, liver and gastrointestinal (GI) tract. There are no plasma biomarkers specific for any acute GVHD target organ. We used a large scale, quantitative proteomic discovery procedure to identify biomarker candidates of skin GVHD and validated the lead candidate, elafin, by ELISA in samples from 492 patients. Elafin was overexpressed in GVHD skin biopsies. Plasma levels of elafin were significantly higher at the onset of skin GVHD, correlated with the eventual maximum grade of GVHD, and were associated with a greater risk of death relative to other known risk factors (hazard ratio of 1.78). We conclude that elafin has significant diagnostic and prognostic value as a biomarker of skin GVHD.
\end{abstract}

\section{Introduction}

Acute graft-versus-host disease (GVHD), the primary cause of non-relapse mortality following allogeneic bone marrow transplantation (BMT), usually presents as a skin rash $(1,2,3)$. The diagnosis of acute GVHD is based on clinical criteria (rash, elevated bilirubin level, nausea and diarrhea) (4) and may be confirmed by biopsy, which is invasive and labor intensive. Rashes are common after BMT and have many etiologies such as allergic reactions to medications or viral exanthems (3). Because the consequences of progressive GVHD are grave, many clinicians initiate treatment of suspected GVHD with systemic high-dose corticosteroids in the absence of a confirmed diagnosis (5). The morbidity of such treatment is significant,

\footnotetext{
"Corresponding author: James Ferrara, MD, Director Blood and Marrow Transplant Program, University of Michigan Comprehensive Cancer Center room 6308, 1500 East Medical Center Drive, Ann Arbor, MI 48109-5942, Ph\# 734-615-1340, Fax\# 734-647-9271, ferrara@umich.edu.

Competing interest's statement

The authors declare that they have no competing financial interests.

Author Contributions: S.P. designed the study, performed all experiments, wrote the paper, and provided funding; T.B. was the study statistician; J.H., H.W., V.F., S.P., Q.Z., A.C. performed proteomics experiments, J.C. and Y. W. performed validation experiments, B.C. and S.O. were the pathologists of the study; J.E.L., S.W.C., C.K., S.M., G.Y., E.P., P.R. contributed to patient accrual, quality control of the clinical endpoints, and paper editing; D.H. contributed to clinical data abstraction; S.H. and J.L.M.F conceived and designed the study, wrote the paper, and provided funding.
} 
particularly in terms of increased risk of infection posed by systemic steroid administration in a population that is already immunosuppressed $(6,7)$. We recently reported that a panel of four plasma proteins (interleukin-2-receptor-alpha (IL-2R $\alpha$ ), tumor-necrosis-factor-receptor-1 (TNFR1), interleukin-8 (IL-8), and hepatocyte growth factor (HGF)) discriminated between patients with GVHD $(\mathrm{N}=182)$ and without GVHD $(\mathrm{N}=242)$ at the time of diagnosis and predicted long term survival independent of GVHD severity (8). None of the biomarkers identified was specific for GVHD in an individual target organ and we did not evaluate whether the panel was able to distinguish between GVHD and other conditions that present with similar symptoms. In the present study, we utilized a mass spectrometry (MS)-based technique as a discovery engine to unambiguously identify candidate plasma biomarkers of skin GVHD. We consequently evaluated the lead candidate, elafin, for its diagnostic and prognostic value in the plasma of 492 allogeneic BMT patients.

\section{Results \\ Discovery Study}

Heparinized plasma samples were collected weekly from 522 patients who received allogeneic BMT at the University of Michigan between 2000 and 2008. All patients received pharmacologic GVHD prophylaxis (usually a calcineurin inhibitor in combination with at least one other agent), and none of the grafts were depleted of T cells. Characteristics of thirty patients in the discovery set are presented in Table S1 and Methods. We used an Intact Protein Analysis System (IPAS) (Figure 1A) to identify candidate biomarker proteins with concentrations at least two fold higher in samples pooled from ten BMT patients presenting with skin GVHD than in pooled samples from ten BMT patients without the disease. The diagnosis of skin GVHD was histologically confirmed by biopsy in all 10 patients (see Methods). Plasma samples from patients of the discovery set were taken at the time of clinical diagnosis of skin GVHD and at equivalent times after BMT in patients with No GVHD. Among 66 candidate biomarker proteins identified and increased at least two fold in GVHD plasma, fourteen were expressed primarily in the skin (Table S2). Elafin, (also known as peptidase inhibitor-3, skin-derived antileukoproteinase or trappin-2), emerged as the lead biomarker candidate because suitable antibodies were available for high throughput screening of plasma samples by ELISA (Table S2). The MS characteristics of elafin are show in Fig. 1B, Fig. S1, and supplementary material. We quantitated elafin levels in separate aliquots of the twenty individual samples pooled in the No GVHD and skin GVHD groups and from ten additional patients presenting with biopsy-proven GVHD of only the gastrointestinal (GI) tract. Elafin levels were three fold higher in patients with skin GVHD compared to each of the other groups (Fig. S2).

\section{Validation Study}

We evaluated elafin as a biomarker of skin GVHD in a validation set of 492 allogeneic BMT recipients who were not included in the discovery set. Patient characteristics are shown in Table 1. GVHD of the skin is often difficult to distinguish from rashes due to other causes (3). We compared elafin protein expression by immunohistochemistry in skin biopsies taken from twenty of these patients, ten with histologically confirmed GVHD and ten whose biopsies were histologically consistent with allergic reactions to medications. Blinded analysis showed that positive elafin expression, defined as significant staining extending to a depth of greater than $50 \%$ of the epidermis, was present in 7/10 cases of GVHD and 0/10 cases of non-GVHD (P = 0.003 , Fig. 2A and B). 0/3 biopsies of normal skin were positive for elafin. Plasma elafin levels of patients with GVHD were 3.9 fold higher than patients with a non-GVHD rash (Fig. 2C, P $<0.001)$. 
We categorized plasma samples of the validation set into four different groups according to the presence or absence of clinical symptoms of GVHD (4): patients presenting with isolated skin GVHD ( $\mathrm{N}=159)$, patients without GVHD ( $=223)$, patients with isolated GI GVHD $(\mathrm{N}=57)$, and patients with a skin rash judged not to be GVHD by either clinical or histological criteria (non-GVHD rash) $(\mathrm{N}=53)$. Patients who presented with GVHD simultaneously in more than one target organ were not included in the analysis. In patients without GVHD, samples were obtained either at the occurrence of the rash or at equivalent time points after BMT. Recipients of grafts from donors who were not family members or who were not HLAmatched were overrepresented in the two GVHD groups. Patients who developed GI GVHD were more likely to have received a reduced intensity conditioning regimen $(\mathrm{P}=0.04)$.

Plasma elafin levels were twice as high in patients with skin GVHD compared to each of the other groups, a finding that was consistent with the result from patients with skin biopsies (P $<0.001$, Fig. 3A). We next analyzed whether elafin levels correlated with the severity of skin GVHD (stages 1 to 4 ) at presentation (4). Elafin levels rose significantly as the GVHD stage increased (Fig 3B) and were significantly different in patients with skin stage 2 versus stage 1 (mean \pm SEM: $8662 \pm 793 \mathrm{pg} / \mathrm{ml}$ vs. $4011 \pm 245 \mathrm{pg} / \mathrm{ml}, \mathrm{P}<0.001$ ).

These two stages are commonly combined in grade I GVHD by the modified Glucksberg scale (4). There was no difference between stage 0 and stage 1 GVHD. We also analyzed plasma elafin levels by the extent of the skin rash. Elafin levels in patients with GVHD rashes were significantly higher than those with non-GVHD rashes for both stage $2(25 \%-50 \%$ body surface area) and stage 3-4 (> 50\% area) (Fig. 3C, P < 0.001). Elafin levels in patients with non-GVHD rashes were similar when the absence of GVHD was established by clinical criteria alone (mean \pm SEM: $3649 \pm 426 \mathrm{pg} / \mathrm{ml}, \mathrm{N}=23$ ) or confirmed by biopsy (mean \pm SEM: 4644 $\pm 564 \mathrm{pg} / \mathrm{ml}, \mathrm{N}=30)$.

We compared the sensitivity of elafin as a unique biomarker of skin GVHD to four previously reported diagnostic biomarkers of systemic acute GVHD (IL-2R $\alpha$, TNFR1, IL-8, HGF) (8). We obtained all five biomarkers in 111 patients with skin rashes: 58 patients with skin GVHD and 53 patients with non-GVHD rash. Patient characteristics were similar between the two groups for age, diagnosis, donor type and match, conditioning regimen intensity and day of sample acquisition after BMT (Table S3). We generated Receiver Operating Characteristic (ROC) curves and found that the area under the curve (AUC) of elafin was the highest $(0.77)$ and the AUC of the composite panel was 0.84 (Fig. 4). These data show that elafin is the best single discriminator for the diagnosis of GVHD in BMT patients with a rash, and that the combination of all five biomarkers further improves the specificity and sensitivity of the test.

\section{Elafin levels have prognostic significance in patients presenting with skin GVHD}

Elafin is an alarm antiprotease secreted in response to antiprotease secreted in response to IL-1 and TNF $\alpha$ (9); we therefore next analyzed whether elafin levels have prognostic significance for patients presenting with GVHD of the skin. We chose the median level of elafin as the cutoff, and divided 159 patients with skin GVHD into two equal groups according to elafin levels: low $(<6000 \mathrm{pg} / \mathrm{ml}, \mathrm{N}=80)$ and high $(\geq 6000 \mathrm{pg} / \mathrm{ml}, \mathrm{N}=79)$. We then determined the non-relapse mortality (NRM) for each group (Fig. 5A). The NRM at 1 year was more than double in the high elafin group and trended toward statistical significance: $28 \%$ [95\% CI, 19\% $-40 \%$ ] vs. $11 \%$ [95\% CI, 6\% - 20\%], P $=0.06$. The causes of NRM were acute GVHD (thirteen), chronic GVHD (five), two idiopathic pneumonia syndrome (two) and venoocclusive disease (one) in the high elafin group and acute GVHD (five), chronic GVHD (one), hemorrhage (one) and undetermined (one) in the low elafin group (Table S4). Patients with high elafin levels at the diagnosis of GVHD died from GVHD and its consequences three times as often as those with low levels at diagnosis $(26 \%$ vs. $8 \%, \mathrm{P}=0.02)$. Mortality from relapse in the first two years was similar in both groups, $28 \%$ [95\% CI, 19\% - 40\%] vs. $23 \%$ [95\% 
CI, $15 \%-35 \%$ ], $\mathrm{P}=0.48$ (Fig. 5B). The five year overall survival was significantly higher in the low elafin group: $48 \%$ [95\% CI, $35 \%-65 \%$ ] vs. $26 \%$ [95\% CI, $16 \%-42 \%$ ], P $=0.011$ (Fig. 5C).

Acute GVHD usually presents with Grade I (Stage 1 or Stage 2) skin disease, but approximately $50 \%$ of patients will not respond to treatment and the severity of disease progresses (5). Linear regression analysis showed that higher elafin levels at the time of diagnosis of skin GVHD correlated with greater stages of skin GVHD but not with greater stages of GI GVHD at the time of maximal GVHD grade $(\mathrm{P}<0.001$ and $\mathrm{P}=0.83$, respectively). This correlation further indicates the specificity of elafin as a biomarker for GVHD of the skin. Elafin levels at the time of diagnosis of skin GVHD also correlated with maximum overall GVHD grade $(\mathrm{P}=0.002)$. We compared elafin levels and the stage of GVHD at presentation for their independent prognostic value in patients presenting with skin GVHD $(\mathrm{N}=159)$. When adjusted for other known prognostic factors (donor type, degree of HLA-match, conditioning intensity, age, and disease status at transplant), a high elafin level at the time of GVHD diagnosis was significantly associated with a greater risk of death (hazard ratio of 1.71 [95\% CI, $1.08 \%-2.69 \%$ ], P = 0.02 ; Table 2) whereas the onset stage ( 1 and 2 vs. 3 and 4 ) of skin GVHD was not associated with mortality risk (Table 2). When survival was modeled simultaneously on elafin level, GVHD skin stage at onset, and the other prognostic factors listed above, the association between elafin level and risk of mortality remained statistically significant $(P=0.02)$. Elafin levels at the time of GVHD diagnosis thus provided important prognostic information independent of the extent of skin GVHD at presentation.

These analyses were performed for all patients with rashes $(\mathrm{N}=212)$. NRM at one year for patients with high elafin levels was $29 \%$ [95\% CI, $20 \%-39 \%$ ] vs. $8 \%$ [95\% CI, $4 \%-15 \%$ ], $(\mathrm{P}=0.003$, Fig. 5D). Mortality from relapse in the first two years was the same in both groups: $28 \%$ [95\% CI, $19 \%-38 \%$ ] vs. $25 \%$ [95\% CI, $18 \%-34 \%$ ], (P = 0.63, Fig. 5E). The five year overall survival was significantly higher in the low elafin group: 53\% [95\% CI, 43\% - 66\%] vs. $29 \%$ [95\% CI, 20\% - 43\%], (P = 0.001, Fig. 5F). When we analyzed overall survival in only the patients presenting with a rash involving $25 \%$ or more body surface area, it was significantly higher in the low elafin group $(\mathrm{N}=60)$ compared to the high elafin group $(\mathrm{N}=$ 83): $54 \%$ [95\% CI, $42 \%-70 \%]$ vs. $29 \%$ [95\% CI, 19\% - 44\%] (P = 0.01).

\section{Discussion}

Elafin, a plasma biomarker specific for a GVHD target organ, was identified as a candidate biomarker by using an in-depth, unbiased, tandem MS-based analysis of plasma that can quantify proteins at low concentrations $(10,11)$. Other MS-based approaches have described spectral patterns associated with GVHD, but have not identified specific proteins $(12,13,14)$. Here, we identify elafin, measure its plasma levels in a large validation set, and analyze both the diagnostic and prognostic value of this biomarker in allogeneic BMT patients.

Elafin was initially identified as an elastase inhibitor overexpressed in inflamed epidermis $(15,16,17)$. Gene expression studies in human keratinocytes have shown that elafin is induced by inflammatory cytokines that mediate GVHD $(9,18)$. The specificity of elafin as a GVHD biomarker may be attributed to its production by target keratinocytes rather than by effector cells capable of damaging all three target organs $(2,3)$. Although produced locally as an antiprotease secreted in response to IL-1 and TNF $\alpha$ (9), elafin was readily detected in the systemic circulation, and plasma elafin levels effectively discriminated between GVHD of the skin from rashes of other etiologies, a common diagnostic dilemma after BMT $(2,3)$. We have previously reported a panel of biomarkers for systemic acute GVHD, but did not evaluate whether the biomarkers could distinguish between GVHD and other conditions presenting with similar symptoms (8). When all five biomarkers were analyzed in BMT patients with rashes, 
elafin performed the best (Fig. 4). Our data provide a proof-of-principle demonstration that biomarkers of disease-related tissue-specific changes can be detected in the plasma of patients, and suggests a diagnostic blood test with promising specificity and sensitivity for GVHD of the skin.

The functions of elafin are multiple and pleiotropic, including antimicrobial activity, priming of innate immune responses and the inhibition of proteases (19). As a pro-inflammatory and antimicrobial agent, elafin enhances the recruitment and function of inflammatory cells in response to endotoxin $(20,21)$ and activates dendritic cells (DCs) $(22,23)$. As an antiinflammatory agent, elafin neutralizes excess damaging proteases released by neutrophils (24) and reduces the tissue necrosis after experimental cardiac transplantation (25). It has been suggested that these seemingly contradictory activities might be reconciled if elafin provides antimicrobial protection while limiting neutrophil-derived inflammation and driving the transition from an innate to an adaptive immune response (19).

Elafin levels may have value not only as a non-invasive diagnostic test but as a prognostic marker. The majority (68\%) of cases of GVHD present at our center as an isolated skin rash similar to the incidence reported in the literature $(1,2,3)$. A difference in elafin levels between stage 1 and 2 skin disease supports the stratification of these two groups as demonstrated in a large retrospective study (26). All patients received pharmacologic GVHD prophylaxis, including those who did not develop GVHD; it is thus unlikely that immunosuppressive drugs altered elafin levels, although this possibility cannot be formally excluded. All samples in this study were obtained within twenty four hours of the initiation of systemic therapy for GVHD, and it is interesting to note that elafin levels correlated with the maximum overall grade of GVHD, which reflects the progression of disease after treatment $(4,27)$. In the multivariate analysis, elafin levels at the onset of skin GVHD also predicted overall survival independently of the area of the extent of the skin rash. Several possibilities may explain this significant prognostic value. First, elafin levels may indicate damage that is not yet clinically evident; in skin GVHD biopsies numerous keratinocytes that were not apoptotic expressed elafin (Fig 2B). Second, increased elafin may indicate damage elsewhere, such as the lung; elafin is produced by bronchial epithelium and alveolar macrophages, and increased levels have been noted prior to the diagnosis of acute respiratory distress syndrome (28). Third, elafin secretion may reflect a chronic process, as in severe psoriasis, where serum elafin levels correlated with disease activity but remained elevated during treatment (29).

Our data are consistent with several other studies that show the GVHD grade at diagnosis does not have prognostic value because it does not correlate with the eventual maximum grade $(30,31,32)$. Determination of elafin levels in patients with possible GVHD of the skin may therefore have significant value to clinicians, and future GVHD grading systems may beneficially incorporate both laboratory and clinical values in determining the optimal therapy for individual patients.

\section{Materials and Methods}

\section{Patients and samples}

All plasma samples were collected prospectively under protocols approved by the Institutional Review Board between 2000 and 2008 and stored at the University of Michigan. Heparinized blood samples were collected weekly for one month after BMT, then monthly for two months and at the time of key clinical events including the development of symptoms consistent with GVHD. Plasma was obtained after Ficoll (Amersham) gradient centrifugation of $20 \mathrm{~mL}$ whole blood that had been collected in heparin containing Vacutainers tubes (Becton Dickinson) to prevent clotting. Samples were aliquoted without additives into cryovials and stored immediately at $-80^{\circ} \mathrm{C}$. Assessments of rash, serum bilirubin level, nausea, and average daily 
stool volume were recorded at the time of sample collection. GVHD was graded based on the severity of involvement of each target organ (4). All samples collected at the time of GVHD diagnosis were obtained within 24 hours of commencement of therapy with systemic corticosteroids. All patients received pharmacologic GVHD prophylaxis with at least two agents, including a calcineurin inhibitor. No donor grafts were depleted of T cells.

Discovery set patients-Patients presenting with isolated skin GVHD stage 2 and 3 ( $\mathrm{N}=$ $10)$, patients without GVHD $(\mathrm{N}=10)$, and patients with isolated GI GVHD $(\mathrm{N}=10)$ were included in the discovery set. Patients were matched for age, intensity of the conditioning regimen, donor source, HLA-match and time of sample acquisition (Table S1). The histologic diagnosis of GVHD was unequivocally confirmed on skin biopsy in all ten patients. Histologic features of acute GVHD include a perivascular inflammatory lymphocytic infiltrate with minimal eosinophils, variable exocytosis in the upper dermis, and vacuolar interface changes with individual keratinocyte apoptosis and lymphocyte satellitosis (lymphocyte associated apoptosis) in the basal layer of the epidermis (33).

Validation set patients-Validation set patients were independent from the discovery set patients. The validation set consisted of four groups: (i) 159 patients evaluated within 24 hours of the onset of isolated skin GVHD (skin GVHD), (ii) 223 patients who never developed GVHD (no GVHD), (iii) 57 patients who presented with isolated GI GVHD (GI GVHD), and (iv) 53 patients with skin rash that were judged inconsistent with GVHD (non-GVHD rash) by either clinical criteria $(\mathrm{N}=23)$ or histological criteria $(\mathrm{N}=30)$ (Table 1). GVHD was confirmed by biopsy in 144/159 patients with skin GVHD, including those with stage 1 GVHD. GI GVHD was confirmed by biopsy in 52/57 patients (32 patients had both upper and lower GI GVHD). All cases were reviewed by a senior staff pathologist and cases with borderline features were reviewed by at least one other senior pathologist to obtain histological consensus. The etiologies of non-GVHD rashes were as follows: drug rashes $=39$ (sulfamethoxazole/ trimethoprim $=5$, dapsone $=3$, cefepime/ceftazidime $=5$, vancomycine $=3$, daptomycine $=$ 1, ciprofloxacin/norfloxacin/levofloxacin $=4, \mathrm{FK} 463=2$, zithromicin $=1, \mathrm{KGF}=2$, cytarabine $=1$, allopurinol $=1$ ), other rashes $=13$ (engraftment syndrome $=5$, leukemia cutis $=3$, fungal $=2$, viral $=1$, actinic granuloma $=1$, rosacea flare $=1$ ), and undetermined $=11.48 / 53$ patients received only topical treatment for their rashes. The 5 patients with engraftment syndrome (defined as fever $>38.5^{\circ} \mathrm{C}$ within 4 days of neutrophil engraftment, no identifiable infectious cause and a rash not attributable to GVHD) received systemic corticosteroids. In 58 patients of group (i) (skin GVHD) and all 53 patients of group (iv) (non-GVHD rash), we obtained all five biomarkers (patient populations are compared in Table S3). 58 and 24 patients in these two groups, respectively, were reported in the first study (8).

\section{Proteomic Analysis}

Sample Preparation-We identified proteins using an IPAS, a MS-based approach that is able to quantitate $70 \%$ of complex protein mixtures across five orders of magnitude of abundance (10,11). $30 \mu \mathrm{l}$ aliquots of plasma were pooled from each of 10 patients without GVHD (No GVHD), and likewise from 10 patients with skin GVHD that were matched for age, intensity of the conditioning regimen, donor source, degree of HLA-match and time of sample acquisition. Pooled plasma was then immunodepleted of the six most abundant proteins (Albumin, IgG, IgA, transferrin, haptoglobin and antitrypsin) using a Hu-6 column (4.6×250mm; Agilent). Recovery of non-depleted proteins was >0.95. Immunodepleted samples were concentrated using Centricon YM-3 devices (Millipore) and re-diluted in $8 \mathrm{M}$ urea, $30 \mathrm{mM}$ Tris pH 8.5, 0.5\% OG (octyl-beta-d-glucopyranoside, Roche). Protein concentrations were determined by the Bradford assay according to the manufacturer's instructions (Pierce). Samples were reduced with dithiothreitol (DTT) in $50 \mu \mathrm{L}$ of $2 \mathrm{M}$ Tris$\mathrm{HCl} \mathrm{pH} 8.5$ (0.66 mg DTT/mg protein), and cysteine residues of intact proteins were labeled 
with acrylamide isotopes. The No GVHD pool was labeled with the light acrylamide isotope $\left({ }^{12} \mathrm{C}\right.$ acrylamide) $(>99.5 \%$ purity, Fluka), and the skin GVHD pool was labeled with the heavy $1,2,3-{ }^{13} \mathrm{C}$ acrylamide isotope $\left({ }^{13} \mathrm{C}\right.$ acrylamide) (> 98\% purity, Cambridge Isotope Laboratories). Alkylation with acrylamide was performed for $1 \mathrm{~h}$ at room temperature by adding ${ }^{12} \mathrm{C}$ acrylamide or ${ }^{13} \mathrm{C}$ acrylamide diluted in $2 \mathrm{M}$ Tris- $\mathrm{HCl} \mathrm{pH} 8.5$ to the protein solution at a ratio of 10/1 (weight/weight).

Protein Fractionation-After isotopic labeling and mixing of the two pools, the sample was diluted to $10 \mathrm{ml}$ with $20 \mathrm{mM}$ Tris in 6\% isopropanol, $4 \mathrm{M}$ Urea - $\mathrm{pH} 8.5$ and immediately injected in an anion exchange column (SAX, $7.5 \mathrm{~mm}$ ID $\times 15 \mathrm{~cm}$ long, Column Technology) using an 8 step-elution (from $0 \mathrm{mM} \mathrm{NaCl}$ to $1000 \mathrm{mM} \mathrm{NaCl}$ ) at $0.8 \mathrm{~mL} / \mathrm{min}$. Fractions from each of the 8 anion-exchange separation elution steps were further separated by reversed-phase chromatography (PorosR2/10, $4.6 \mathrm{~mm}$ ID $\times 100 \mathrm{~mm}$ column, Applied Biosystems). A $25 \mathrm{~min}$ gradient elution (from $5 \%$ to $95 \%$ mobile phase B) was used at $2.4 \mathrm{~mL} / \mathrm{min}$. Mobile phase A for anion-exchange chromatography consisted of $20 \mathrm{mM}$ Tris (Sigma), 6\% isopropanol (Fisher), 4 M Urea, pH 8.5 and mobile phase B was the same composition and $\mathrm{pH}$ as phase A with the addition of $1 \mathrm{M} \mathrm{NaCl}$ (Fisher). For reversed-phase chromatography, the mobile phase A consisted of $95 \%$ water, $5 \%$ acetonitrile, $0.1 \%$ trifluoroacetic acid (TFA) (Supelco) and mobile phase B consisted of $90 \%$ acetonitrile, $10 \%$ water, $0.1 \%$ TFA. Sixty fractions of 900 $\mu \mathrm{l}$ were collected from each of the 8 pools for a total of 480 fractions. Samples were lyophilized after reversed phase chromatography and reconstituted in $0.25 \mathrm{M}$ urea containing $50 \mathrm{mM}$ ammonium bicarbonate and 4\% acetonitrile for tryptic digestion. After overnight incubation, the resulting peptide mixtures were acidified with $5 \mathrm{uL}$ of $1 \%$ formic acid prior to mass spectrometry shotgun analysis. Protein recovery following separation was $>0.95$. Aliquots of $200 \mu \mathrm{l}$ of each fraction contained approximately $20 \mu \mathrm{g}$ of protein.

Mass spectrometry analysis-We digested the $200 \mu \mathrm{l}$ aliquot of each fraction with 200 ng modified trypsin in $25 \mathrm{uL}$ of $0.25 \mathrm{M}$ urea with $50 \mathrm{mM}$ ammonium bicorbonate. Individual digested fractions \#4 to \#60 from each reverse-phase run were pooled in 12 fractions, corresponding to a total of 96 fractions. Digests were analyzed by shotgun mass spectrometry using the hybrid linear ion trap - Fourier Transform (LTQ-FT) mass spectrometer (ThermoFinnigan) coupled to a 2D nanoLC (Eksigent). The liquid chromatography separation was performed in a $25 \mathrm{~cm}$ column (Picofrit $75 \mu \mathrm{m}$ ID, New Objectives, in house-packed with MagicC18 resin) using a 90-min linear gradient from $5 \%$ to $40 \%$ of acetonitrile in $0.1 \%$ formic acid at $300 \mathrm{nl} / \mathrm{min}$. The spectra were acquired in a data-dependent mode in $\mathrm{m} / \mathrm{z}$ range of 400 to 1800 . The 5 most abundant +2 or +3 ions of each MS spectrum were selected for MS/MS analysis.

Protein identification-The acquired liquid chromatography-tandem mass spectrometry (LC-MS/MS) data from a single analysis were automatically processed by the Computational Proteomics Analysis System - CPAS (34). Database searches were performed to identify proteins using X!Tandem against the human IPI (International Protein Index) database v.3.29 using a tryptic search (35). Cysteine alkylation with ${ }^{12} \mathrm{C}$ acrylamide $(+71.03657)$ was set as a fixed modification and ${ }^{13} \mathrm{C}$ acrylamide $(+3.01006)$ and oxidation of Methionine $(+15.99491)$ as variable modifications. The database search results were then analyzed by PeptideProphet (36) and ProteinProphet (37) software. 1961 proteins with ProteinProphet scores $\geq 0.95$ (5\% error rate) were identified with high confidence. ProteinProphet was also used to remove redundant protein names.

Quantitative analysis of protein levels-Quantitative ratios of proteins were obtained by comparison of cysteines labeled with ${ }^{12} \mathrm{C}$ and ${ }^{13} \mathrm{C}$ acrylamide isotopes. Quantitative information was extracted using a script designated "Q3ProteinRatioParser," developed to 
quantify each pair of peptides containing cysteine residues identified by MS/MS (11). Only peptides with a minimum of 0.75 PeptideProphet score, and mass deviation less than $20 \mathrm{ppm}$ were considered for quantitation. Ratios of ${ }^{13} \mathrm{C} /{ }^{12} \mathrm{C}$ acrylamide labeled peptides were plotted on a histogram ( $\log 2$ scale) and the median of the distribution was centered at zero. All normalized peptide ratios for a specific protein were averaged to compute an overall protein ratio. Additional details of the MS/MS database search, protein identification and quantitation are provided in Supplemental materials.

\section{Immunohistochemical evaluation of skin biopsies}

Formalin fixed skin biopsies from 20 patients in the validation set with GVHD $(\mathrm{N}=10)$, nonGVHD-rash $(\mathrm{N}=10)$, as well as normal skin $(\mathrm{N}=3)$ were immunohistochemically stained using a polyclonal antibody directed against elafin (FL-117, dilution 1:250; Santa Cruz Biotechnology). Positive expression was defined as significant staining of at $50 \%$ of the depth of the epidermis, excluding the granular cell layer and the acrosyringium. Blinded samples were independently verified by two pathologists. Original magnification 400X.

\section{ELISA assays}

Elafin antibody pairs were purchased from R\&D systems (Duoset $\left.{ }^{\circledR}\right)$ and measurements were performed according to the manufacturer's protocol. Samples (diluted 1/20) and standards were run in duplicate, absorbance was measured using a SpectraMax-Plus-384 and results were calculated with SoftMax-Pro v4.7.1 (Molecular Devices). Details of the assay parameters are provided in Table S5.

\section{Statistical Analysis}

The statistical methods used for IPAS are described above. Elafin levels from individual samples in the discovery set were compared using ANOVA. Differences in characteristics between patient groups were assessed with a Kruskal-Wallis test for continuous values and chi-squared tests of association for categorical values. Differences in elafin staining of skin biopsies were assessed with Fisher's Exact Test. Linear regression was used to assess the trend in elafin levels with maximum grade of skin GVHD, maximum overall grade and future GI involvement. The ROC AUC was estimated nonparametrically. Logistic regression models were used to assess the association of elafin with skin GVHD in combination with other biomarkers. Non-relapse mortality (NRM) and relapse mortality were modeled using cumulative incidence regression methods as described in Fine et al. (38). Overall survival (OS) was modeled using Cox regression methods.

\section{Supplementary Material}

Refer to Web version on PubMed Central for supplementary material.

\section{Acknowledgments}

Supported by grants from the National Institutes of Health (P01-CA039542-20 and RC1-HL-101102), the Cancer Center Core (P30 CA46592), the Doris Duke Charitable Foundation (20020347), and the American Cancer Society (CRP 08-224-01).

\section{References}

1. Vogelsang GB, Lee L, Bensen-Kennedy DM. Pathogenesis and treatment of graft-versus-host disease after bone marrow transplant. Annu Rev Med 2003;54:29-52. [PubMed: 12359826]

2. Ferrara JL, Levine JE, Reddy P, Holler E. Graft-versus-host disease. Lancet 2009:1550-1561. [PubMed: 19282026] 
3. Antin, JH.; Deeg, HJ. Clinical spectrum and pathophysiology of acute graft-vs.-host disease. In: Ferrara, J.; Cooke, K.; Deeg, HJ., editors. Graft-vs-Host Disease. Marcel Dekker, Inc; New York: 2005. p. 369-381.

4. Przepiorka D, Weisdorf D, Martin P, Klingemann HG, Beatty P, Hows J, Thomas ED. 1994 Consensus Conference on Acute GVHD Grading. Bone Marrow Transpl 1995;15:825-828.

5. Cutler, C.; Antin, JH. Manifestation and Treatment of Acute Graft-Versus-Host-Disease. In: Appelbaum, F.; Forman, SJ.; Negrin, RS.; Blume, KG., editors. Thomas' Hematopoietic Cell Transplantation. Blackwell Publishing Ltd; 2009. p. 1287-1303.

6. Van Lint MT, Milone G, Leotta S, Uderzo C, Scime R, Dallorso S, Locasciulli A, Guidi S, Mordini N, Sica S, Cudillo L, Fagioli F, Selleri C, Bruno B, Arcese W, Bacigalupo A. Treatment of acute graftversus-host disease with prednisolone: significant survival advantage for day +5 responders and no advantage for nonresponders receiving anti-thymocyte globulin. Blood 2006;107:4177-4181. [PubMed: 16449522]

7. Deeg HJ. How I treat refractory acute GVHD. Blood 2007;109:4119-4126. [PubMed: 17234737]

8. Paczesny S, Krijanovski OI, Braun TM, Choi SW, Clouthier SG, Kuick R, Misek DE, Cooke KR, Kitko CL, Weyand A, Bickley D, Jones D, Whitfield J, Reddy P, Levine JE, Hanash SM, Ferrara JL. A biomarker panel for acute graft-versus-host disease. Blood 2009;113:273-278. [PubMed: 18832652]

9. Pfundt R, Wingens M, Bergers M, Zweers M, Frenken M, Schalkwijk J. TNF-alpha and serum induce SKALP/elafin gene expression in human keratinocytes by a p38 MAP kinase-dependent pathway. Arch Dermatolog Res 2000;292:180-187.

10. Faca V, Pitteri SJ, Newcomb L, Glukhova V, Phanstiel D, Krasnoselsky A, Zhang Q, Struthers J, Wang H, Eng J, Fitzgibbon M, McIntosh M, Hanash S. Contribution of protein fractionation to depth of analysis of the serum and plasma proteomes. J Proteome Res 2007;6:3558-3565. [PubMed: 17696519]

11. Faca V, Coram M, Phanstiel D, Glukhova V, Zhang Q, Fitzgibbon M, McIntosh M, Hanash S. Quantitative analysis of acrylamide labeled serum proteins by LC-MS/MS. J Proteome Res 2006;5:2009-2018. [PubMed: 16889424]

12. Kaiser T, Kamal H, Rank A, Kolb HJ, Holler E, Ganser A, Hertenstein B, Mischak H, Weissinger EM. Proteomics applied to the clinical follow-up of patients after allogeneic hematopoietic stem cell transplantation. Blood 2004;104:340-349. [PubMed: 15054046]

13. Srinivasan R, Daniels J, Fusaro V, Lundqvist A, Killian JK, Geho D, Quezado M, Kleiner D, Rucker S, Espina V, Whiteley G, Liotta L, Petricoin E, Pittaluga S, Hitt B, Barrett AJ, Rosenblatt K, Childs RW. Accurate diagnosis of acute graft-versus-host disease using serum proteomic pattern analysis. Exp Hematol 2006;34:796-801. [PubMed: 16728285]

14. Weissinger EM, Schiffer E, Hertenstein B, Ferrara JL, Holler E, Stadler M, Kolb HJ, Zander A, Zurbig $\mathrm{P}$, Kellmann M, Ganser A. Proteomic patterns predict acute graft-versus-host disease after allogeneic hematopoietic stem cell transplantation. Blood 2007;109:5511-5519. [PubMed: 17339419]

15. Alkemade JA, Molhuizen HO, Ponec M, Kempenaar JA, Zeeuwen PL, de Jongh GJ, van VlijmenWillems IM, van Erp PE, van de Kerkhof PC, Schalkwijk J. SKALP/elafin is an inducible proteinase inhibitor in human epidermal keratinocytes. J Cell Sci 1994;107(Pt 8):2335-2342. [PubMed: 7983189]

16. Nonomura K, Yamanishi K, Yasuno H, Nara K, Hirose S. Up-regulation of elafin/SKALP gene expression in psoriatic epidermis. J Invest Dermatol 1994;103:88-91. [PubMed: 8027586]

17. Wiedow O, Schroder JM, Gregory H, Young JA, Christophers E. Elafin: an elastase-specific inhibitor of human skin. Purification, characterization, and complete amino acid sequence. J Biol Chem 1990;265:14791-14795. [PubMed: 2394696]

18. Ferrara JL, Levine JE, Reddy P, Holler E. Graft-versus-host disease. Lancet 2009;373:1550-1561. [PubMed: 19282026]

19. Williams SE, Brown TI, Roghanian A, Sallenave JM. SLPI and elafin: one glove, many fingers. Clin Sci (Lond) 2006;110:21-35. [PubMed: 16336202]

20. McMichael JW, Roghanian A, Jiang L, Ramage R, Sallenave J. The antimicrobial antiproteinase elafin binds to lipopolysaccharide and modulates macrophage responses. Am J Respir Cell Mol Biol 2005;32:443-452. [PubMed: 15668324] 
21. Sallenave JM, Cunningham GA, James RM, McLachlan G, Haslett C. Regulation of pulmonary and systemic bacterial lipopolysaccharide responses in transgenic mice expressing human elafin. Infect Immun 2003;71:3766-3774. [PubMed: 12819058]

22. Roghanian A, Williams SE, Sheldrake TA, Brown TI, Oberheim K, Xing Z, Howie SE, Sallenave JM. The antimicrobial/elastase inhibitor elafin regulates lung dendritic cells and adaptive immunity. Am J Respir Cell Mol Biol 2006;34:634-642. [PubMed: 16424380]

23. Kolls JK, McCray PB Jr, Chan YR. Cytokine-mediated regulation of antimicrobial proteins. Nat Rev Immunol 2008;8:829-835. [PubMed: 18949018]

24. Vachon E, Bourbonnais Y, Bingle CD, Rowe SJ, Janelle MF, Tremblay GM. Anti-inflammatory effect of pre-elafin in lipopolysaccharide-induced acute lung inflammation. Biol Chem 2002;383:1249-1256. [PubMed: 12437112]

25. Cowan B, Baron O, Crack J, Coulber C, Wilson GJ, Rabinovitch M. Elafin, a serine elastase inhibitor, attenuates post-cardiac transplant coronary arteriopathy and reduces myocardial necrosis in rabbits afer heterotopic cardiac transplantation. J Clin Invest 1996;97:2452-2468. [PubMed: 8647937]

26. Rowlings P, Przepiorka D, Klein J, Gale R, Passweg J, Henslee-Downey P, Cahn J, Calderwood S, Gratwohl A, Socie G, Abecasis M, Sobocinski K, Zhang M, Horowitz M. IBMTR severity Index for grading acute graft-versus-host disease: restrospective comparison with Glucksberg grade. Brit J Haematol 1997;97:855-864. [PubMed: 9217189]

27. Cahn JY, Klein JP, Lee SJ, Milpied N, Blaise D, Antin JH, Leblond V, Ifrah N, Jouet JP, Loberiza F, Ringden O, Barrett AJ, Horowitz MM, Socie G. Prospective evaluation of 2 acute graft-versushost (GVHD) grading systems: A joint Societe Francaise de Greffe de Moelle et Therapie Cellulaire (SFGM-TC), Dana Farber Cancer Institute (DFCI), and International Bone Marrow Transplant Registry (IBMTR) prospective study. Blood 2005;106:1495-1500. [PubMed: 15878974]

28. Wang Z, Chen F, Zhai R, Zhang L, Su L, Lin X, Thompson T, Christiani DC. Plasma neutrophil elastase and elafin imbalance is associated with acute respiratory distress syndrome (ARDS) development. PLoS ONE 2009;4:e4380. [PubMed: 19197381]

29. Alkemade HA, de Jongh GJ, Arnold WP, van de Kerkhof PC, Schalkwijk J. Levels of skin-derived antileukoproteinase (SKALP)/elafin in serum correlate with disease activity during treatment of severe psoriasis with cyclosporin A. J Invest Dermatol 1995;104:189-193. [PubMed: 7829874]

30. Cragg L, Blazar BR, Defor T, Kolatker N, Miller W, Kersey J, Ramsay M, McGlave P, Filipovich A, Weisdorf D. A randomized trial comparing prednisone with antithymocyte globulin/prednisone as an initial systemic therapy for moderately severe acute graft-versus-host disease. Biol Blood Marrow Transpl 2000;6:441-447.

31. MacMillan ML, Weisdorf DJ, Wagner JE, DeFor TE, Burns LJ, Ramsay NK, Davies SM, Blazar BR. Response of 443 patients to steroids as primary therapy for acute graft-versus-host disease: comparison of grading systems. Biol Blood Marrow Transpl 2002;8:387-394.

32. Weisdorf D, Haake R, Blazar B, Miller W, McGlave P, Ramsay N, Kersey J, Filipovich A. Treatment of moderate/severe acute graft-versus-host disease after allogeneic bone marrow transplantation: an analysis of clinical risk features and outcome. Blood 1990;75:1024-1030. [PubMed: 2302454]

33. Wagner, JL.; Murphy, GF. Pathology and Pathogenesis of Cutaneous Graft-vs.-Host Disease. In: Ferrara, JLM.; Cooke, KR.; Deeg, HJ., editors. Graft-vs-Host Disease. Marcel Dekker, Inc; New York: 2005. p. 229-255.

34. Rauch A, Bellew M, Eng J, Fitzgibbon M, Holzman T, Hussey P, Igra M, Maclean B, Lin CW, Detter A, Fang R, Faca V, Gafken P, Zhang H, Whitaker J, States D, Hanash S, Paulovich A, McIntosh MW. Computational Proteomics Analysis System (CPAS): An extensible, open-source analytic system for evaluating and publishing proteomic data and high throughput biological experiments. J Proteome Res 2006;5:112-121. [PubMed: 16396501]

35. MacLean B, Eng JK, Beavis RC, McIntosh M. General framework for developing and evaluating database scoring algorithms using the TANDEM search engine. Bioinformatics 2006;22:2830-2832. [PubMed: 16877754]

36. Keller A, Nesvizhskii AI, Kolker E, Aebersold R. Empirical statistical model to estimate the accuracy of peptide identifications made by MS/MS and database search. Anal Chem 2002;74:5383-5392. [PubMed: 12403597] 
37. Nesvizhskii AI, Keller A, Kolker E, Aebersold R. A statistical model for identifying proteins by tandem mass spectrometry. Anal Chem 2003;75:4646-4658. [PubMed: 14632076]

38. Fine JP, Gray RJ. A proportional hazards model for the subdistribution of a competing risk. J Am Stat Assoc 1999;94:496-509. 
A

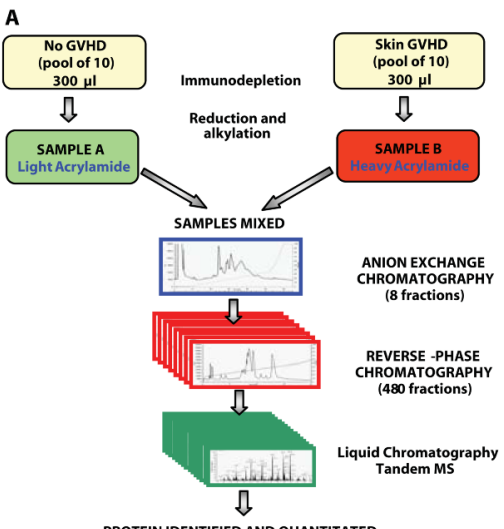

B

$b_{1} b_{2} b_{3} b_{4} b_{5} b_{6} b_{7} b_{8} b_{9} b_{10} b_{11} b_{12}$

92 C*LLDTDC*PGI KK ${ }^{103}$

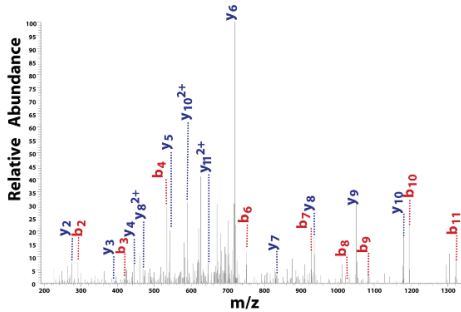

$y_{12} y_{11} y_{10} y_{9} y_{8} y_{3} y_{6} y_{5} y_{4} y_{3} y_{2} y_{1}$

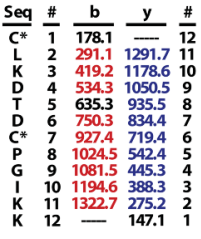

Elafin Sequence

N terminus-MRASSFLIW VFLLAGTLVL EAAVTGVPVK GQDTVKGRVP FNGQDPVKGQ VSVKGQDKVK AQEPVKGPVS TKPGSCPIIL IRCAMLNPPN RCLKDTDCPG IKKCCEGSCG MACFVPQ -C terminus

Figure 1. Proteomic workflow for elafin discovery

A) Overview of the proteomic workflow for Intact Protein Analysis System (IPAS).

B) Tandem mass spectrum of the identified peptide, elafin. $b_{n}$ or $y_{n}$ denotes the fragment ion generated by cleavage of the peptide bond after the $n t h$ amino acid containing either the peptide $\mathrm{N}$-terminus (b series) or the $\mathrm{C}$-terminus (y series), respectively. The identified b- and y-ions and all fragment ion mass/charge $(\mathrm{m} / \mathrm{z})$ values are indicated in the table. $\mathrm{C}^{*}$ denotes cysteine residues modified by acrylamide containing $3{ }^{13} \mathrm{C}$ atoms. The identified peptide sequence location is written in bold in the protein sequence. 

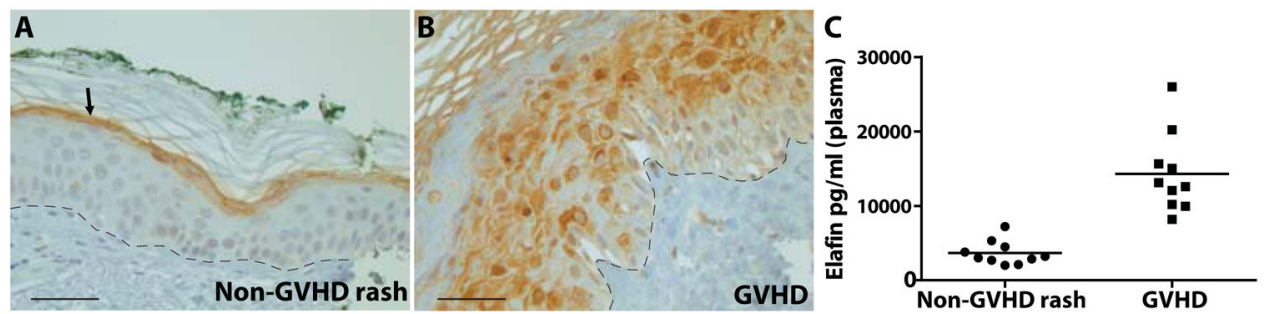

Figure 2. Skin biopsies from BMT patients

Skin biopsies from BMT patients with rashes immunohistochemically stained for elafin. A) Biopsies histologically confirmed as drug hypersensitivity showed staining only in the granular cell layer (arrow). B) Biopsies histologically confirmed as GVHD showed a strong positive staining of at least $50 \%$ of the layers in epidermis. Scale bar $=50 \mu \mathrm{m}$, the dashed line represents the epidermal/dermal junction. C) Plasma elafin levels in biopsied patients ( $\mathrm{N}=10$ per group). 
A

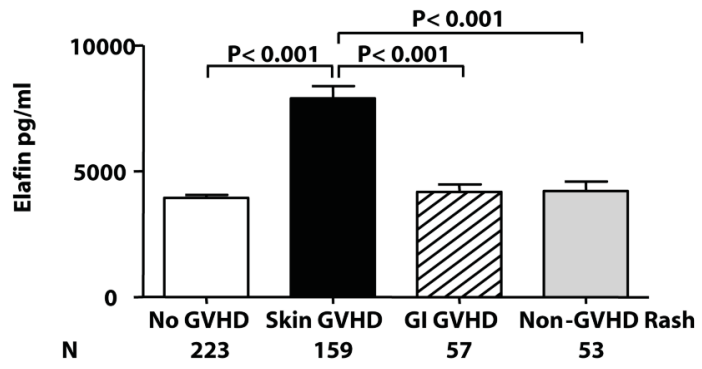

B

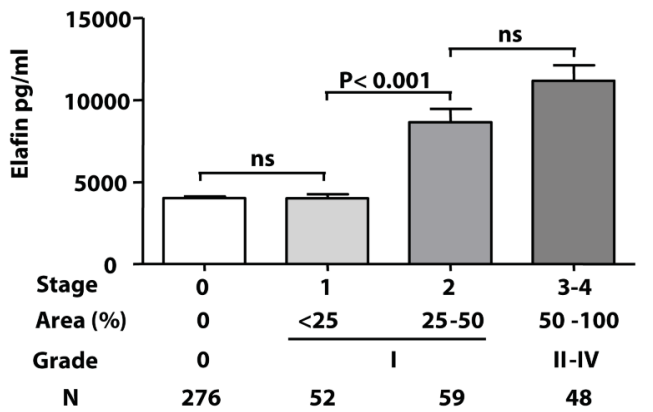

C

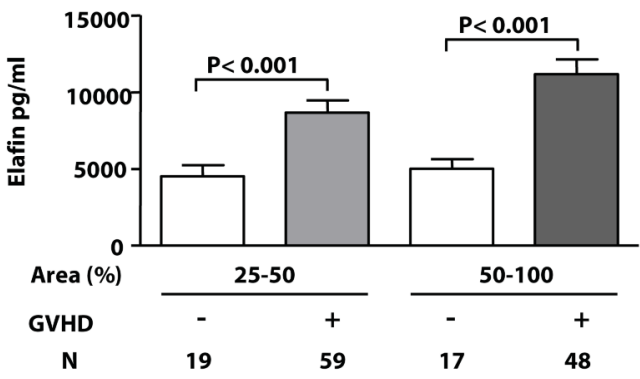

Figure 3. Elafin plasma levels in BMT patients of the validation set

A) Plasma elafin levels in BMT patient samples measured by ELISA. B) Plasma elafin levels stratified to the stage of skin GVHD at presentation. C) Elafin levels in patients with rashes covering equivalent percentages of body surface area (Area). 


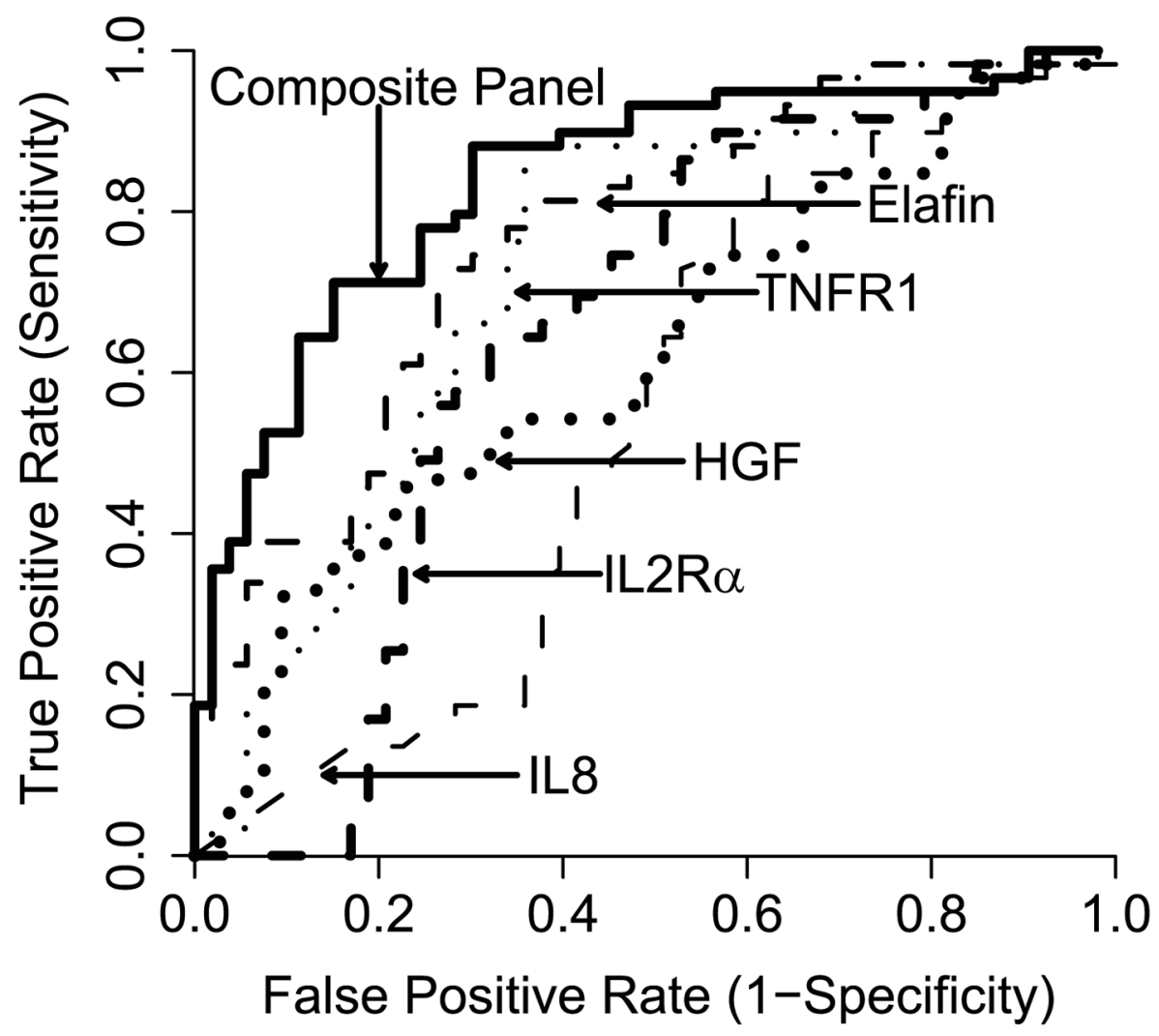

Figure 4. ROC curves comparing skin GVHD and non-GVHD rashes

ROC curves for Elafin, TNFR1, IL-2R $\alpha$, HGF, IL-8 and the composite curve of all five biomarkers (AUC $=0.77,0.73,0.65,0.62,0.54$ and 0.84 , respectively) comparing patients with skin-GVHD (N=58) vs. non-GVHD rash $(\mathrm{N}=53)$. 

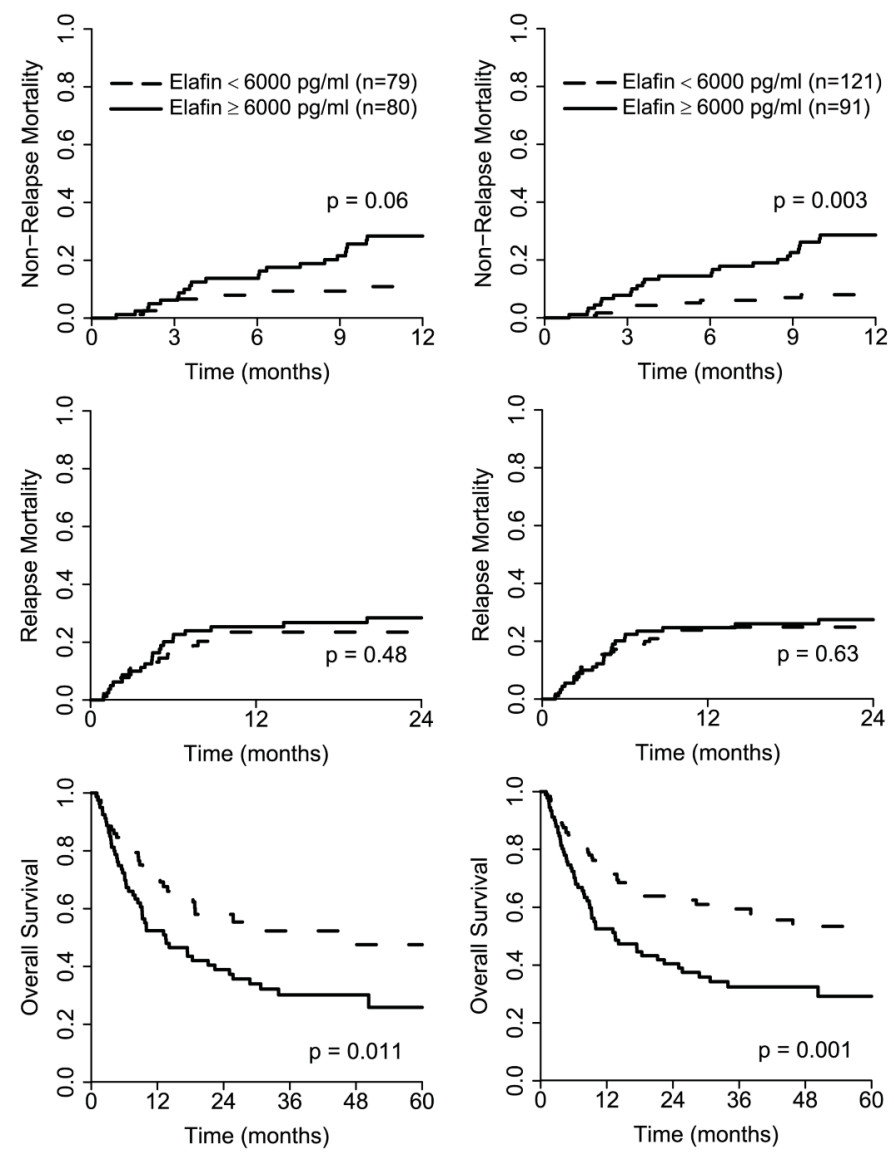

Figure 5. Nonrelapse mortality (NRM), relapse, and overall survival (OS) according to plasma elafin levels in BMT patients with rashes

Patients with GVHD of the skin $(\mathrm{N}=159)$ were divided into two equal groups according to elafin level: low ( $<6000 \mathrm{pg} / \mathrm{ml}, \mathrm{N}=79)$ and high $(\geq 6000 \mathrm{pg} / \mathrm{ml}, \mathrm{N}=80)$. The cumulative incidence of NRM (A), relapse mortality (B) and overall survival (C) were determined by Kaplan Meier and plotted for each group. The same analysis was performed for all BMT patients with rashes $(\mathrm{N}=212, \mathrm{D}-\mathrm{F})$. 


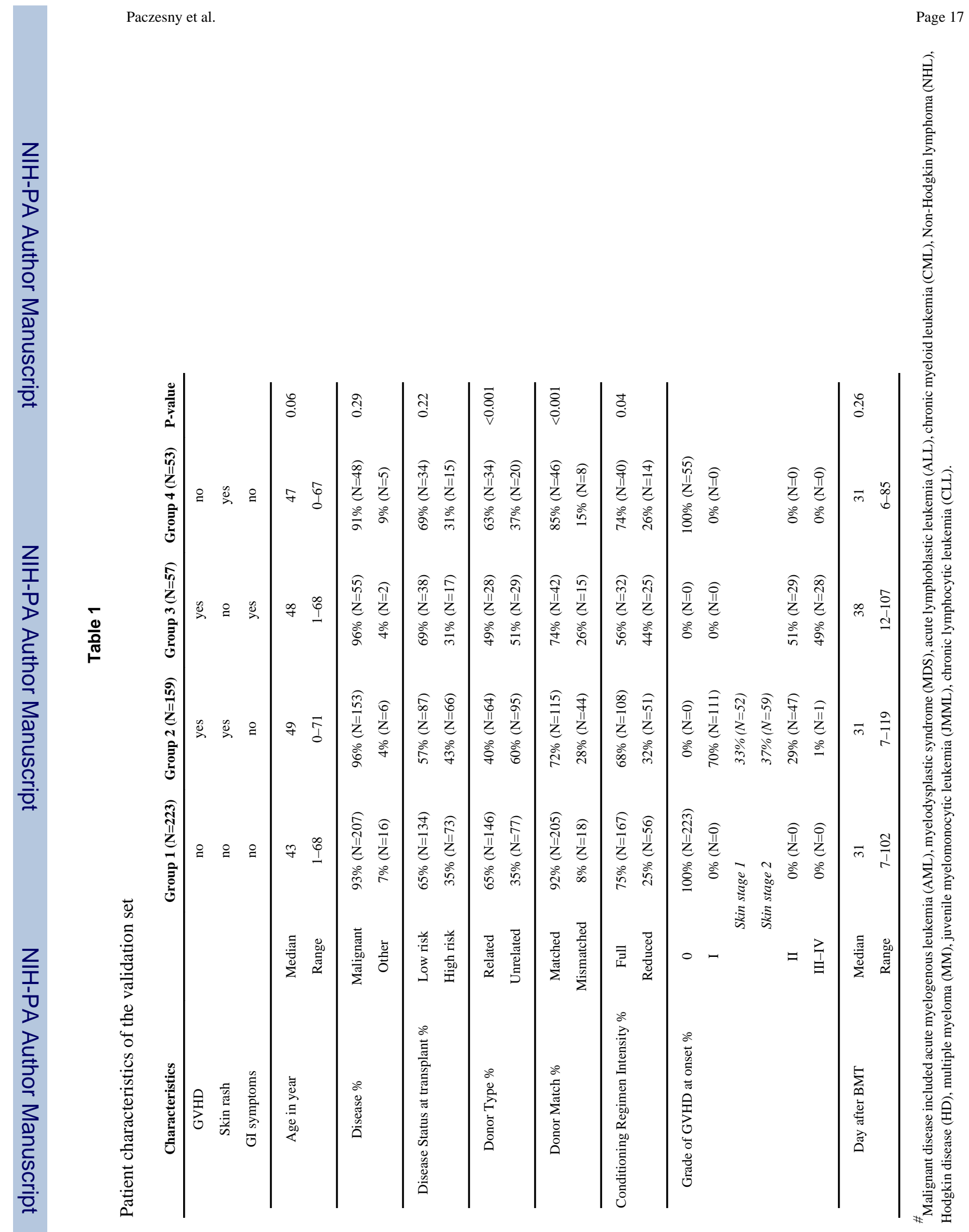




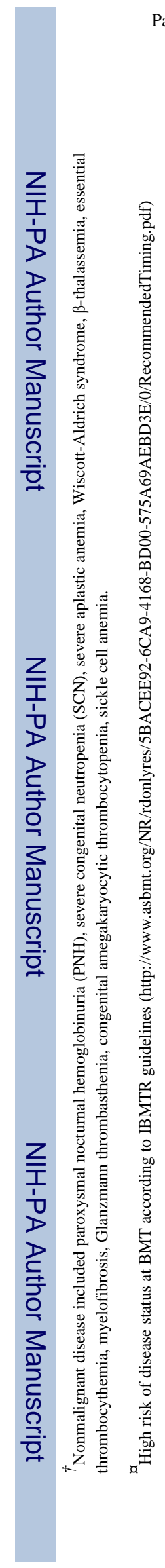


Table 2

Elafin levels at onset of skin GVHD predict overall survival independent of initial skin stage

\begin{tabular}{|c|c|c|c|c|}
\hline & \multicolumn{2}{|c|}{ Independent * } & \multicolumn{2}{|c|}{ Simultaneous * } \\
\hline & $\underline{\text { Hazard Ratio }}$ & $p$-value & $\underline{\text { Hazard Ratio }}$ & $p$-value \\
\hline GVHD Skin Stage (3-4 vs. 1-2) & 1.06 & 0.82 & 0.88 & 0.60 \\
\hline Elafin levels (High vs. Low) & 1.71 & 0.02 & 1.78 & 0.02 \\
\hline
\end{tabular}

*Adjusted for age, donor type, HLA-match, conditioning intensity, disease status at transplant 